\title{
Dynamic aspects of the LHRH system associated with ovulation in the little brown bat (Myotis lucifugus)
}

\author{
E. L. P. Anthony*, P. J. Weston*,.J. A. Montvilo*§, T. O. Bruhn†, K. Neel* \\ and J. C. King $\ddagger$
}

*Department of Biology, Rhode Island College, Providence, RI 02908, USA; †Division of Endocrinology, Rhode Island Hospital, Providence, RI 02903, USA; $\ddagger$ Department of Anatomy and Cellular Biology, Tufts University Schools of Medicine, Boston, MA 02111, USA; and \$Science Department, Bryant College, Smithfield, RI 02917, USA

\begin{abstract}
Summary. Adult female bats were collected from natural roosting sites in pre-ovulatory and post-ovulatory conditions. LHRH neurones of these animals were examined using light and electron microscopic immunocytochemistry, and LHRH tissue contents were measured by radioimmunoassay. Comparisons between the two groups of bats revealed that the number of LHRH perikarya detected immunocytochemically, as well as hypothalamic LHRH content, were significantly reduced in post-ovulatory animals. Distributions of immunoreactive perikarya were, however, strikingly similar in both groups. The reduction in immunoreactive cell number observed after ovulation was therefore not restricted to an anatomically defined subset of neurones, but was evident throughout the population.

The projection of LHRH-immunoreactive fibres that extend into the pituitary neural lobe in this species also exhibited changes related to endocrine condition. Morphometric indices of fibre density in the neural lobe were significantly reduced in post-ovulatory bats, as was LHRH content of the lower infundibular stalk and neural lobe.

Fine structural study of perikarya revealed complex anatomical interactions between LHRH-immunopositive elements, especially in post-ovulatory bats. These interactions included direct apposition of perikarya, as well as more elaborate networks involving various combinations of perikarya and large- and small-caliber processes.

These changes in the LHRH system associated with ovulation suggest reduction of stored peptide within perikarya and depletion from terminals within the lower infundibular stem and neural lobe. Parallel reductions in hypothalamic and neural lobe LHRH content during the periovulatory period support the hypothesis that the neural lobe component of the system contributes to control of gonadotrophin secretion in this species. Finally, increased complexity of anatomical contact between components of the LHRH system may be related to activation of this cell population in spring.
\end{abstract}

Keywords: bat; LHRH; ovulation; neurohypophysis; ultrastructure

\section{Introduction}

The little brown bat (Myotis lucifugus) is a hibernating seasonal breeder that exhibits several interesting reproductive specializations. Among these is the phenomenon of delayed ovulation. Females of the species develop a single Graafian follicle in one ovary in autumn. This follicle is then maintained in a pre-ovulatory condition throughout the hibernation period. Mating occurs 
primarily in the fall, although the bats may also mate during periodic arousals from hibernation in winter. Females subsequently store spermatozoa within the reproductive tract throughout the rest of the hibernation period. Ovulation occurs in spring, after final arousal from hibernation, and the single oocyte is fertilized by a stored spermatozoon. These bats ovulate during their annual migration from winter to summer habitats (Wimsatt, 1944). In the north-eastern United States, this migration occurs in April.

In a previous seasonal study of pituitary gonadotrophs in this species, a dramatic reduction of luteinizing hormone ( $\mathrm{LH})$ immunoreactivity was observed in bats collected in late April (after ovulation) compared to that in hibernating animals collected in February (Anthony \& Gustafson, 1984), suggesting that $\mathrm{LH}$ is secreted in the periovulatory period in amounts sufficient to reduce pituitary stores greatly. Furthermore, after ovulation, pituitary LH immunoreactivity does not return immediately to the levels characteristic of hibernation. Instead, it increases gradually during the ensuing periods of pregnancy and lactation.

It was the purpose of this study to extend these seasonal investigations to include the hypothalamic luteinizing hormone-releasing hormone (LHRH) system. Our initial examinations of LHRH neurones in this bat revealed various characteristics that differ remarkably from those of rats. In the little brown bat, LHRH-immunoreactive neuronal perikarya are widely dispersed within the ventral forebrain, extending from olfactory areas to the mamillary bodies. They are most densely aggregated, however, in the medial basal hypothalamus within and around the arcuate nuclei (King et al., 1984). In addition, fibres extending from these neurones do not appear to terminate in the external zone of the median eminence. Instead, most of these fibres pass through the internal zone of the median eminence and the infundibular stalk, and terminate in the pituitary neural lobe (Anthony et al., 1984). In radioimmunoassay, the LHRH-immunoreactive peptide within the lower infundibular stem and neural lobe exhibits a dilution curve parallel to that of synthetic mammalian LHRH. Furthermore, this peptide co-elutes with synthetic LHRH in reverse-phase highperformance liquid chromatography (Anthony et al., 1987). These data provide strong evidence that the stalk/neural lobe projection detectable by immunocytochemistry contains authentic decapeptide LHRH.

The present study focuses on a comparison of the LHRH system in pre- and post-ovulatory bats, as the periovulatory period is the phase of the annual cycle characterized by the most distinct changes in pituitary $\mathrm{LH}$ immunoreactivity. Included in this study are comparisons of total numbers, distributions, and fine structural characteristics of LHRH-immunoreactive perikarya in these two groups of bats. Immunocytochemical observations are accompanied by comparisons of hypothalamic LHRH content determined by radioimmunoassay. We have also carefully examined the stalk/neural lobe projection to determine whether there are changes in this component of the LHRH system associated with ovulation. These data will suggest whether neural lobe LHRH contributes to control of gonadotrophin secretion in this species.

\section{Materials and Methods}

Collection of animals. Pre-ovulatory bats were collected from a hibernation cave in eastern New York state (USA; $44^{\circ} \mathrm{N}, 73^{\circ} 30^{\prime} \mathrm{W}$ ) in late March. Post-ovulatory bats were collected in late April from a maternity roost in the state of New Hampshire $\left(43^{\circ} 40^{\prime} \mathrm{N}, 72^{\circ} 5^{\prime} \mathrm{W}\right)$. These post-ovulatory animals were collected as soon as possible after their migration from the cave environment. Bats were transported in cages designed to minimize stress (see Gustafson \& Belt, 1981) and were killed within $24 \mathrm{~h}$ of capture.

Tissue preparation. Bats were killed by cervical dislocation. The brain was exposed by removal of the calvaria and was carefully removed from the cranium after severing the pituitary stalk. For immunocytochemical studies, the brain was fixed for $45 \mathrm{~min}$ in $10 \%$ acrolein in $0.1 \mathrm{M}$-phosphate buffer (pH 7.2). Removal of the brain exposed the pituitary gland, which was excised along with a small portion of the sphenoid bone and fixed for 10 min in the same fixative.

For determination of LHRH content by radioimmunoassay, removal of the brain was followed by dissection of the hypothalamus. The rostral cut was made $1 \mathrm{~mm}$ anterior to the optic chiasma and the caudal cut immediately behind the mamillary bodies. The tissue block was limited superiorly by the anterior commissure and laterally by the 
hypothalamic sulci. Each hypothalamus was then placed in a $12 \times 75 \mathrm{~mm}$ polypropylene tube and frozen on solid $\mathrm{CO}_{2}$. The neurointermediate component of each pituitary (representing the lower infundibular stem, neural lobe, and intermediate lobe: see Fig. 1) was also placed in a tube and frozen on solid $\mathrm{CO}_{2}$ after it was dissected free from the anterior lobe. After collection of all tissues, hot $\left(95^{\circ} \mathrm{C}\right) 1 \mathrm{M}$-acetic acid was added to each tube ( $1 \mathrm{ml}$ for hypothalami and $0.5 \mathrm{ml}$ for neural lobes) and the tubes were boiled in a water bath for $10 \mathrm{~min}$. Each sample was then sonicated and centrifuged for $30 \mathrm{~min}(5000 \mathrm{~g})$ at $4^{\circ} \mathrm{C}$. Supernatants were collected, evaporated to dryness by vacuum centrifugation, and stored at $-20^{\circ} \mathrm{C}$ until assayed.

Immunocytochemistry. Fixed brains were sectioned coronally on a Vibratome at a thickness of $50 \mu \mathrm{m}$. Sections were collected serially and placed alternately into one of three reaction vials. Pituitaries were cut horizontally, and all sections were placed in one reaction vial.

Pretreatment of these tissues and the immunocytochemical procedures used have been described in detail previously (Anthony \& King, 1986). The two primary antisera to LHRH used in this study were IJ-29 (a gift of Dr Ivor Jackson) and A-R422 (a gift of Dr Akira Arimura). All pituitary sections and one vial of tissue from each brain were treated with IJ-29 (1:500 preabsorbed with $0.25 \%$ bovine thyroglobulin: Sigma Chemical Company, St Louis, MO, USA). The second vial of brain sections was treated with A-R422 (1:500 preabsorbed with 1\% bovine serum albumin: Sigma Chemical Company). The third vial was used either for absorption controls or for labelling of peptides other than LHRH. For absorptions, $1 \mu \mathrm{g}$ synthetic mammalian LHRH (Peninsula Laboratories, Belmont, CA, USA) was added to $1 \mathrm{ml}$ diluted primary antiserum. Tissues were incubated in primary antiserum for $36 \mathrm{~h}$ at $8^{\circ} \mathrm{C}$. Reaction product was produced using diaminobenzidine as the chromagen following peroxidase-antiperoxidase immunocytochemistry. All pituitary sections and most of the brain sections were mounted on glass slides for light microscopic analysis. Selected brain sections were further processed for electron microscopy as described by Anthony \& King (1986).

Cell counts and distributions. All LHRH-immunoreactive perikarya were counted and their positions mapped on bat brain atlas figures (J. C. King \& E. L. P. Anthony, unpublished). Data were recorded separately for Antisera IJ-29 and A-R422. Because only one-third of the sections from each brain were reacted with each antiserum, the number of cells observed was multiplied by three to obtain an estimate of the total number of cells revealed by each antiserum.

To compare the rostro-caudal distribution patterns of LHRH-immunoreactive neurones in pre- and postovulatory bats, the forebrain was divided into 5 regions. The most rostral region $(\mathrm{OL})$ included the olfactory lobes and anterior portions of the septum. The next region (DB) contained the diagonal band of Broca. The preoptic area was included in the third region (PO) and the fourth (AH) represented the anterior hypothalamic area. The most caudal region analysed was the posterior hypothalamic area $(\mathrm{PH})$ which included the arcuate nuclei and the median eminence. To compare the medio-lateral distribution of perikarya in the two groups of bats, 21 domains of equal size were established (designated as $\mathrm{A}$ through $\mathrm{U}$ ), representing sagittal slices through the forebrain. Domain $\mathrm{K}$ was assigned to the midline; Domains $A$ and $U$ represented the most lateral regions on either side of midline.

Morphometric analysis of stalk/neural lobe fibre density. A point-counting technique was used to compare the densities of LHRH-immunoreactive fibres in the lower infundibular stem and the neural lobe in pre- and postovulatory bats. The external zone of the median eminence was excluded from this analysis, as in this species immunoreactive fibres are rarely observed there. A grid consisting of 256 squares was superimposed on Vibratome sections of the pituitary gland in precise and reproducible locations for separate measurements of fibre density in the lower infundibular stem and neural lobe (Fig. 1). Sections were examined at a magnification of $\times 1000$ using an oilimmersion lens.

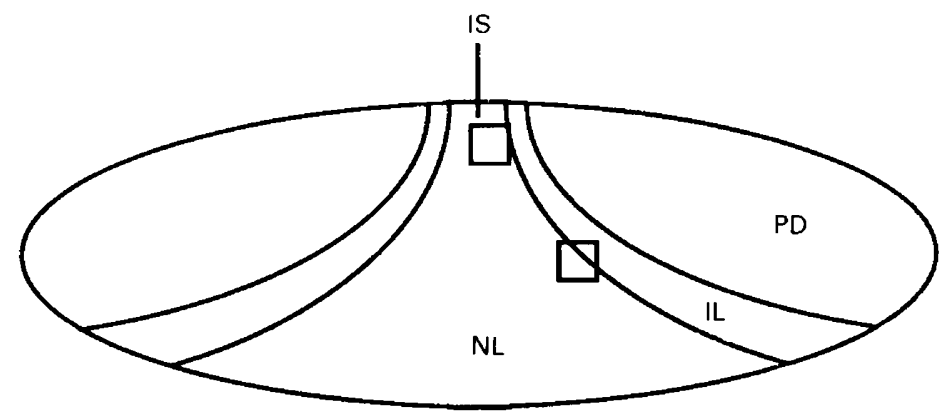

Fig. 1. Diagram representing a horizontal section taken from the dorsal part of the bat pituitary. In this bat, the lower infundibular stem (IS) crosses the dorsal surface of the pars distalis (PD) and pars intermedia (PI) before widening to form the neural lobe (NL). Sites of grid placements used to quantify LHRH-immunoreactive fibre density in the lower infundibular stem and neural lobe are shown. A lateral grid placement was chosen in the neural lobe because most of the LHRH-immunoreactive fibres diverge laterally and course along the border of the intermediate lobe (Anthony et al., 1984). 
Table 1. Mean ( \pm s.e.m.) numbers of LHRHimmunoreactive neurones detected with two different primary antisera in pre- and post-ovulatory bats

\begin{tabular}{lcc}
\hline & $\begin{array}{c}\text { Pre-ovulatory } \\
\text { bats }(\mathrm{N}=6)\end{array}$ & $\begin{array}{c}\text { Post-ovulatory } \\
\text { bats }(\mathrm{N}=7)\end{array}$ \\
\hline IJ-29 & $423 \cdot 0 \pm 42 \cdot 3$ & $280 \cdot 3 \pm 18 \cdot 7^{*}$ \\
A-R422 & $129 \cdot 0 \pm 27 \cdot 1$ & $17 \cdot 6 \pm 4 \cdot 2^{*}$ \\
\hline
\end{tabular}

${ }^{*} P<0.01$ compared with pre-ovulatory value $(t$ test $)$.

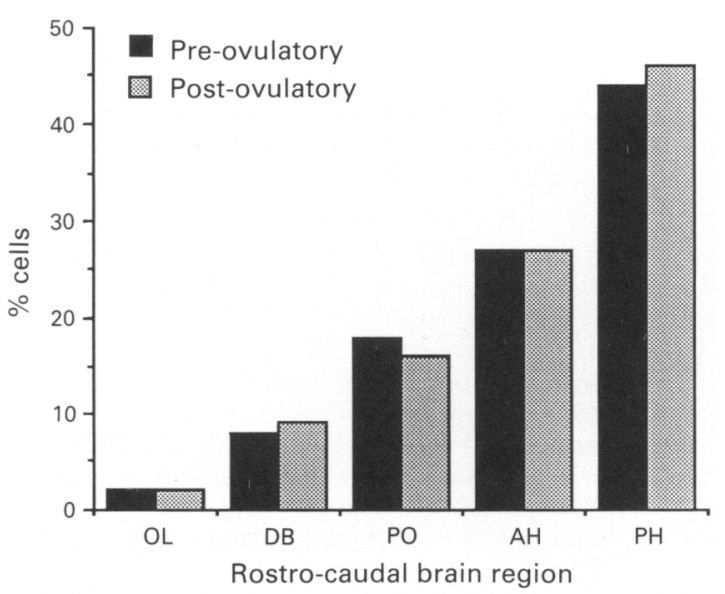

Fig. 2. Comparison of the rostro-caudal distributions of LHRH-immunoreactive perikarya in pre- and post-ovulatory bats. For analysis, the forebrain was divided into 5 regions listed from rostral to caudal: olfactory lobes and anterior septum (OL), diagonal band of Broca (DB), preoptic area $(\mathrm{PO})$, anterior hypothalamic area $(\mathrm{AH})$ and posterior hypothalamic area $(\mathrm{PH})$.

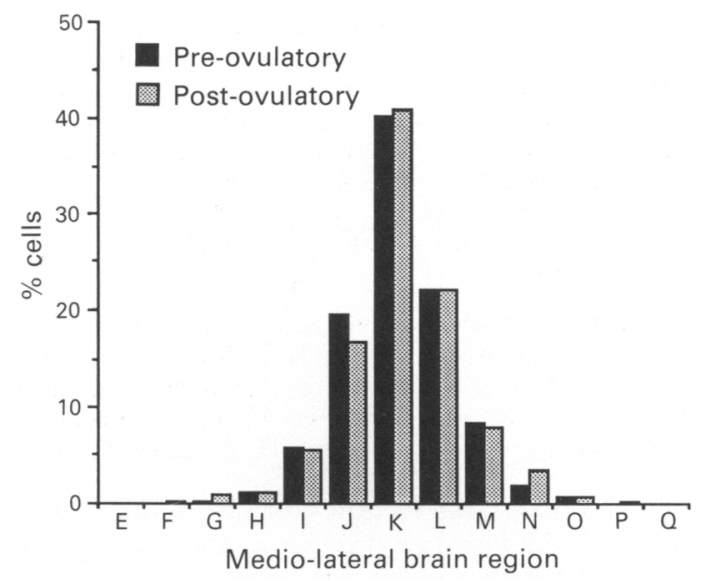

Fig. 3. Comparison of the medio-lateral distributions of LHRH-immunoreactive perikarya in pre- and post-ovulatory bats. For analysis, the forebrain was divided into 21 domains, with ' $\mathrm{K}$ ' representing the midline, and ' $\mathrm{A}$ ' and ' $\mathrm{U}$ ' representing the most lateral regions. Only domains $\mathrm{F}$ through $\mathrm{P}$ contained immunoreactive perikarya. 
Table 2. Indices (see text) of LHRH-fibre density in the lower infundibular stem and neural lobe of pre- and post-ovulatory bats

\begin{tabular}{lcc}
\hline & $\begin{array}{c}\text { Pre-ovulatory } \\
\text { bats }(\mathrm{N}=6)\end{array}$ & $\begin{array}{c}\text { Post-ovulatory } \\
\text { bats }(\mathrm{N}=7)\end{array}$ \\
\hline $\begin{array}{l}\text { Infundibular } \\
\text { stem }(\mathrm{N}=6)\end{array}$ & $0.24 \pm 0.02$ & $0.23 \pm 0.02$ \\
$\begin{array}{l}\text { Neural lobe } \\
(\mathrm{N}=5)\end{array}$ & $0.22 \pm 0.03$ & $0.13 \pm 0.01^{*}$ \\
\hline
\end{tabular}

Values are mean \pm s.e.m.

${ }^{*} P<0.05$ compared with pre-ovulatory value ( $t$ test).

Table 3. LHRH content (pg/tissue), determined by radioimmunoassay, in pre- and post-ovulatory bats

\begin{tabular}{lcc}
\hline & $\begin{array}{c}\text { Pre-ovulatory } \\
\text { bats }(\mathrm{N}=6)\end{array}$ & $\begin{array}{c}\text { Post-ovulatory } \\
\text { bats }(\mathrm{N}=6)\end{array}$ \\
\hline $\begin{array}{l}\text { Hypothalamus } \\
\begin{array}{l}\text { Infundibular } \\
\text { stem/neural } \\
\text { lobe }\end{array}\end{array}$ & $850 \cdot 3 \pm 118 \cdot 6$ & $444 \cdot 8 \pm 125 \cdot 3^{*}$ \\
\hline
\end{tabular}

Values are mean \pm s.e.m.

${ }^{*} P<0.05$ compared with pre-ovulatory value ( $t$ test).

An index of fibre density was used in this analysis. If a sharply focused LHRH immunoreactive fibre or varicosity appeared under an intersection of lines on the grid (a grid point), then that point was counted as a point intersect $(\mathrm{Pi})$. If no immunoreactivity was evident under a grid point, or if apparent immunoreactivity could not be sharply focused, then that point was counted as (Px). All planes of focus were examined using the fine focus adjustment. The index of fibre density was calculated as $\mathrm{Pi} / \mathrm{Pt}$, where $\mathrm{Pt}$ represents total grid points counted $(\mathrm{Pi}+\mathrm{Px})$. Only points lying over infundibular stem or neural lobe tissue were included in the analysis, with a maximum of 289 points of intersect on the grid.

Radioimmunoassay. LHRH tissue contents were measured for pre- and post-ovulatory bats in a single radioimmunoassay. All samples were reconstituted in assay buffer $(100 \mathrm{~mm}$-phosphate containing $0.5 \%$ bovine serum albumin, $\mathrm{pH}$ 7.4). Hypothalamic extracts were assayed in duplicate at 2 dilutions. Neural lobe extracts were assayed in duplicate at 3 dilutions. Samples and standards were incubated with antiserum R42 (Dr Terry Nett) for $24 \mathrm{~h}$ at $4^{\circ} \mathrm{C}$. Iodinated synthetic mammalian LHRH (prepared by the solid-phase lactoperoxidase method) was then added and incubation continued for $24 \mathrm{~h}$. Total incubation volume was $0.5 \mathrm{ml}$ and the final antiserum dilution was 1:400 000 . Free hormone was separated from bound by adsorption with a charcoal suspension $(0 \cdot 1 \%)$. In this assay, the minimum detection level (ED95) was $0.3 \mathrm{pg} /$ tube and the half-maximum displacement (ED50) was $2.6 \mathrm{pg} /$ tube. Interand intra-assay coefficients of variation were $8 \cdot 6 \%$ and $4 \cdot 3 \%$, respectively.

Verification of reproductive condition. The reproductive condition of all bats included in this study was verified by histological examination of both ovaries. The ovaries were fixed in Bouin's fluid, dehydrated in a graded ethanol series, cleared in xylene and embedded in paraffin wax. Serial sections were cut at a thickness of $10 \mu \mathrm{m}$ and stained with haematoxylin and eosin. Bats were verified as post-ovulatory if a corpus luteum was present. In pre-ovulatory bats, no corpus luteum was observed, and in most of these animals a single Graafian follicle was evident.

\section{Results}

\section{Light microscopic immunocytochemistry}

Brains of 6 pre-ovulatory and 7 post-ovulatory bats were used for light microscopic immunocytochemical study of the LHRH system. In both groups of animals, LHRH-immunoreactive 

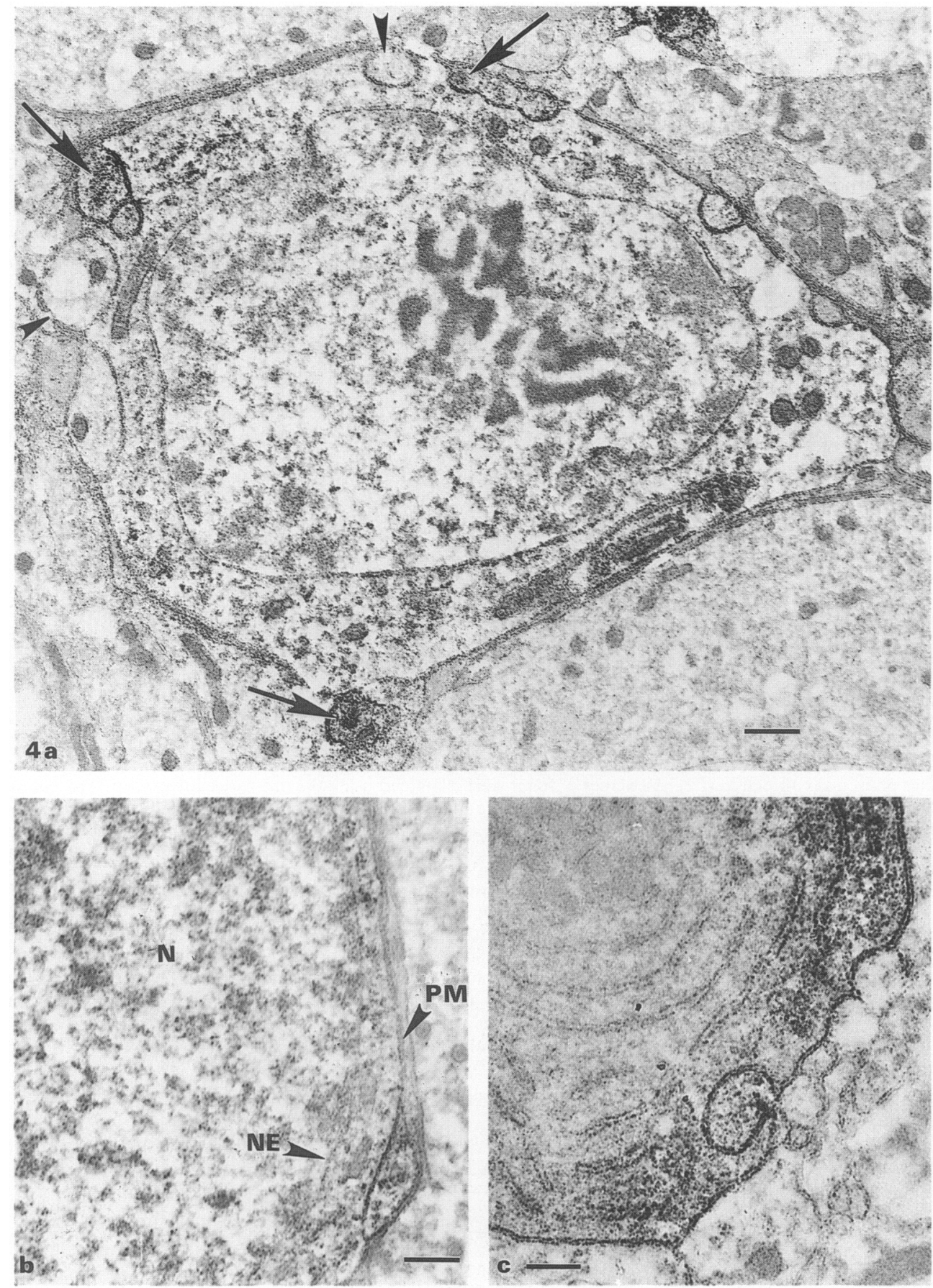
perikarya were distributed throughout the basal forebrain, but were most abundant within the region of the arcuate nuclei. Perikarya were immunoreactive with both primary antisera used; however, more neurones were consistently detected with IJ-29 than with A-R422. Total cell numbers obtained with these antisera are presented in Table 1 . These results reveal a significant reduction in the number of immunoreactive perikarya in post-ovulatory bats compared to the preovulatory group. Although this reduction was observed with both antisera, it was especially evident with A-R422.

To determine whether this post-ovulatory reduction in LHRH-immunoreactivity was limited to any particular subpopulation of these widely dispersed cells, distributions of immunoreactive neurones were compared in the two groups of bats. As is shown in Figs 2 and 3, the rostro-caudal and medio-lateral distributions of LHRH neurones within the forebrain were strikingly similar in both groups of bats. Reduced total cell counts in post-ovulatory bats therefore did not result from a depletion of immunoreactive LHRH from any discretely localized group of neurones but instead reflected decreased numbers of immunoreactive cells throughout the cell population.

Analyses of immunoreactive LHRH fibres in these two groups of bats focused on the projection into the lower infundibular stem and pituitary neural lobe, as fibres were only occasionally observed in the external zone of the median eminence. Morphometric analyses showed that fibre density within the neural lobe was significantly lower in post-ovulatory bats compared to pre-ovulatory animals (Table 2). Fibre density within the lower infundibular stem did not differ significantly between groups.

\section{Radioimmunoassay}

Analyses of hypothalamic and neural lobe LHRH content by radioimmunoassay showed (Table 3) significant differences between pre- and post-ovulatory bats that paralleled the changes observed by immunocytochemistry. Hypothalamic LHRH content was reduced by $48 \%$ in postovulatory compared to pre-ovulatory bats. Similarly, infundibular stem/neural lobe content was $46 \%$ lower in post-ovulatory animals.

\section{Electron microscopy}

The fine structure of LHRH-immunoreactive perikarya was studied in 6 pre- and 5 postovulatory bats ( 44 and 21 cells, respectively). All cells included in this analysis were located in the region of the arcuate nuclei. In all bats, these perikarya were characterized by a thin rim of cytoplasm surrounding the nucleus. Reaction product was distributed throughout the cytoplasm, and was more distinct in pre-ovulatory than in post-ovulatory bats. Free polyribosomes and mitochondria were abundant in the perinuclear region. The nucleus was often irregular in contour and deeply indented. The rough endoplasmic reticulum was usually sparse, represented by short cisternae. Occasionally, stacks of elongated cisternae were observed, but this variation did

Fig. 4. Examples of Type I LHRH-LHRH neuronal contact. (a) An LHRH-immunoreactive perikaryon from a post-ovulatory bat is directly contacted by both small immunopositive (arrows) and small immunonegative (arrowheads) fibres. Contacts with the small immunopositive fibres are classified as Type I interactions in this study. Some of these immunopositive fibres are also in direct contact with each other. Antiserum IJ-29; bar $=0.5 \mu \mathrm{m}$. (b) A Type I contact between an LHRH-immunoreactive perikaryon and an LHRH fibre. The profile of the fibre is shown in its entirety. Parts of the perikaryon included in the photograph are a portion of the nucleus (N), the nuclear envelope (NE) and the plasma membrane (PM). Antiserum IJ29; bar $=0.5 \mu \mathrm{m}$. (c) A Type I contact in which the profile of an LHRH-immunoreactive fibre is almost completely embedded within the cytoplasm of an immunoreactive perikaryon. Antiserum IJ-29; bar $=0.5 \mu \mathrm{m}$. 


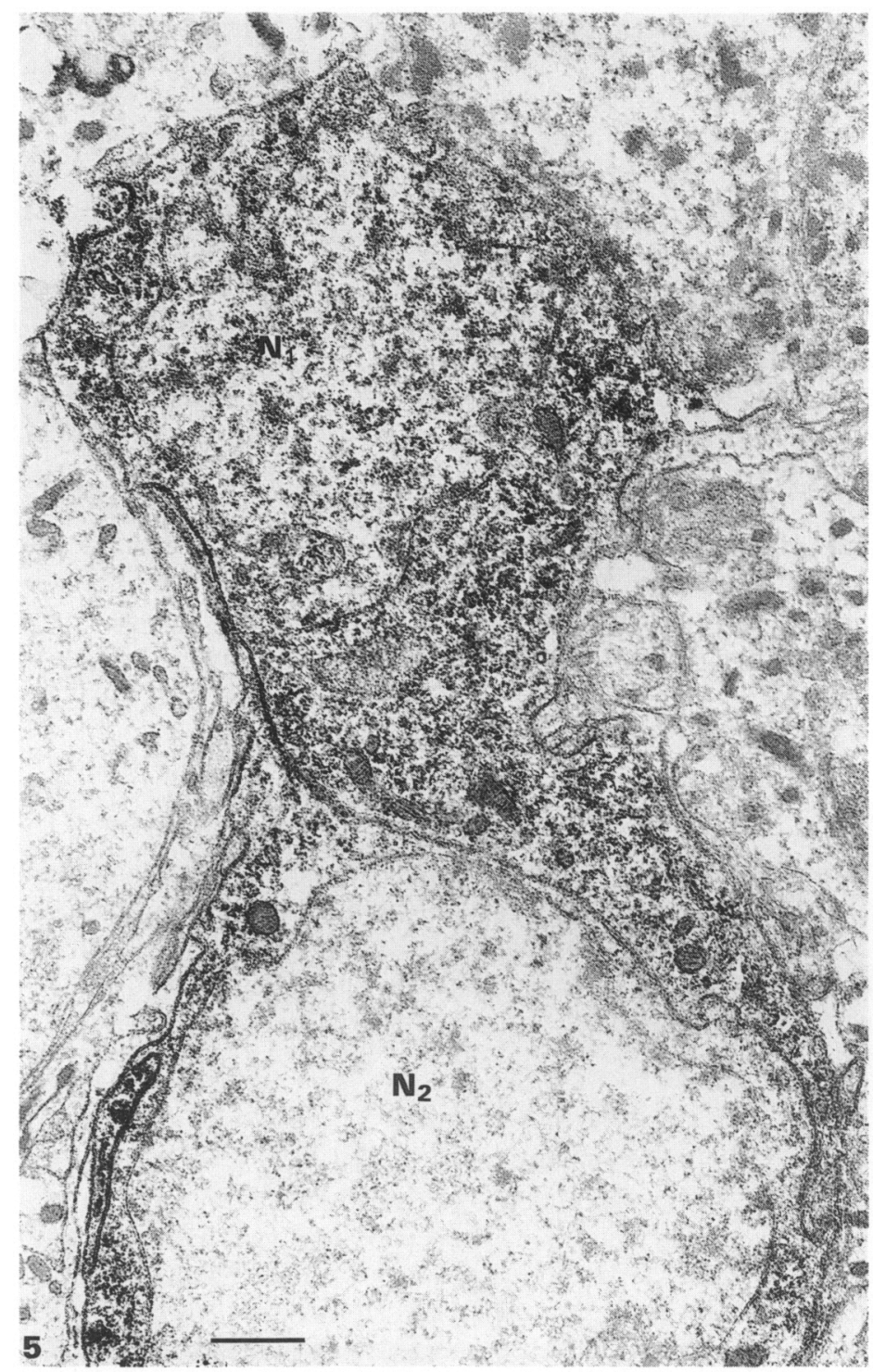

Fig. 5. An example of a Type II interaction from a pre-ovulatory bat, in which two LHRHimmunoreactive perikarya are in direct membrane apposition. The upper cell is more heavily labelled, with reaction product located both in the cytoplasm and within the nucleus $\left(\mathrm{N}_{1}\right)$. Cytoplasmic structures in the lower cell are less heavily labelled, and the nucleus $\left(\mathrm{N}_{2}\right)$ is unlabelled. Antiserum IJ-29; bar $=1 \mu \mathrm{m}$.

not show any consistent relationship with the pre- or post-ovulatory conditions. Immunoreactive secretory granules were observed within perikarya and proximal segments of processes in pre- and post-ovulatory bats, although these granules were not numerous in either group.

The features exhibiting the most clear relationship with endocrine state were the types and extent of direct contacts among LHRH-immunopositive structures. Direct contacts between LHRH-immunopositive perikarya and LHRH-immunopositive fibres were numerous in pre- and post-ovulatory bats. However, these interactions were more extensive and complex in the postovulatory group. Several different types of interaction were observed. In the most common type of 


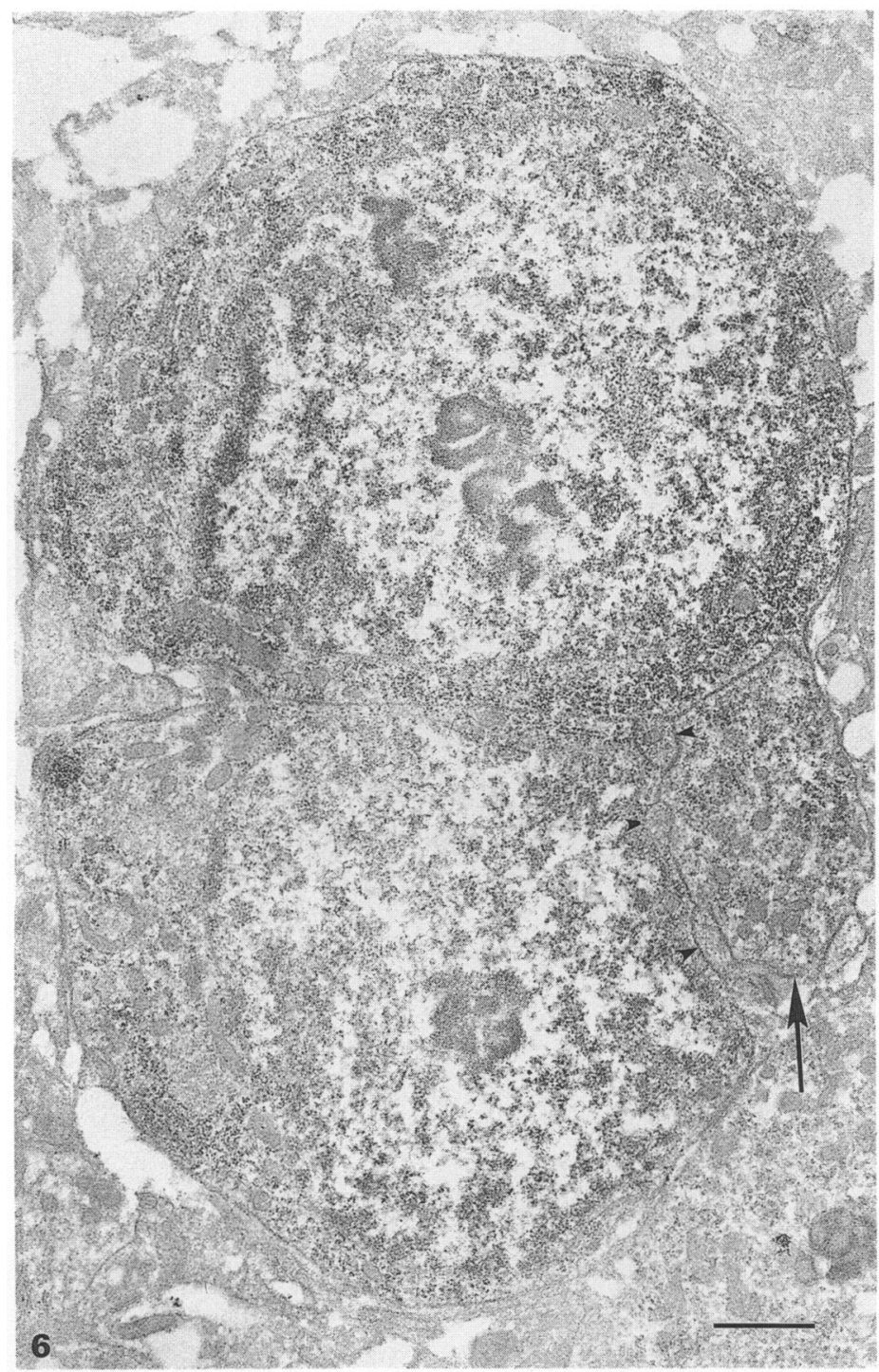

Fig. 6. An example of a Type III interaction in a post-ovulatory bat, in which two lightly LHRH-immunoreactive perikarya are in direct membrane apposition, and both are contacted by at least one immunopositive process (arrow). Three other smaller neuronal fibres are included in the complex (small arrowheads), but due to the light labelling which is typical of tissue from post-ovulatory bats it is difficult to determine whether these also represent LHRH fibres. Antiserum IJ-29; bar $=1 \mu \mathrm{m}$.

contact (Type I), one or more small immunoreactive fibres directly abutted the plasma membrane of an immunoreactive perikaryon (Figs $4 \mathrm{a}-\mathrm{c}$ ). In some of these axosomatic interactions, the fibres were deeply embedded, being partly or completely surrounded by the cytoplasm of an immunoreactive cell (Fig. 4c). In another type of contact (Type II), direct membrane apposition between two immunoreactive perikarya or between a perikaryon and a large-calibre process extended over relatively long distances (Fig. 5).

In the most elaborate examples of interaction (Type III), complexes were observed which involved both of the previously described types of contacts. In one case, two immunoreactive 


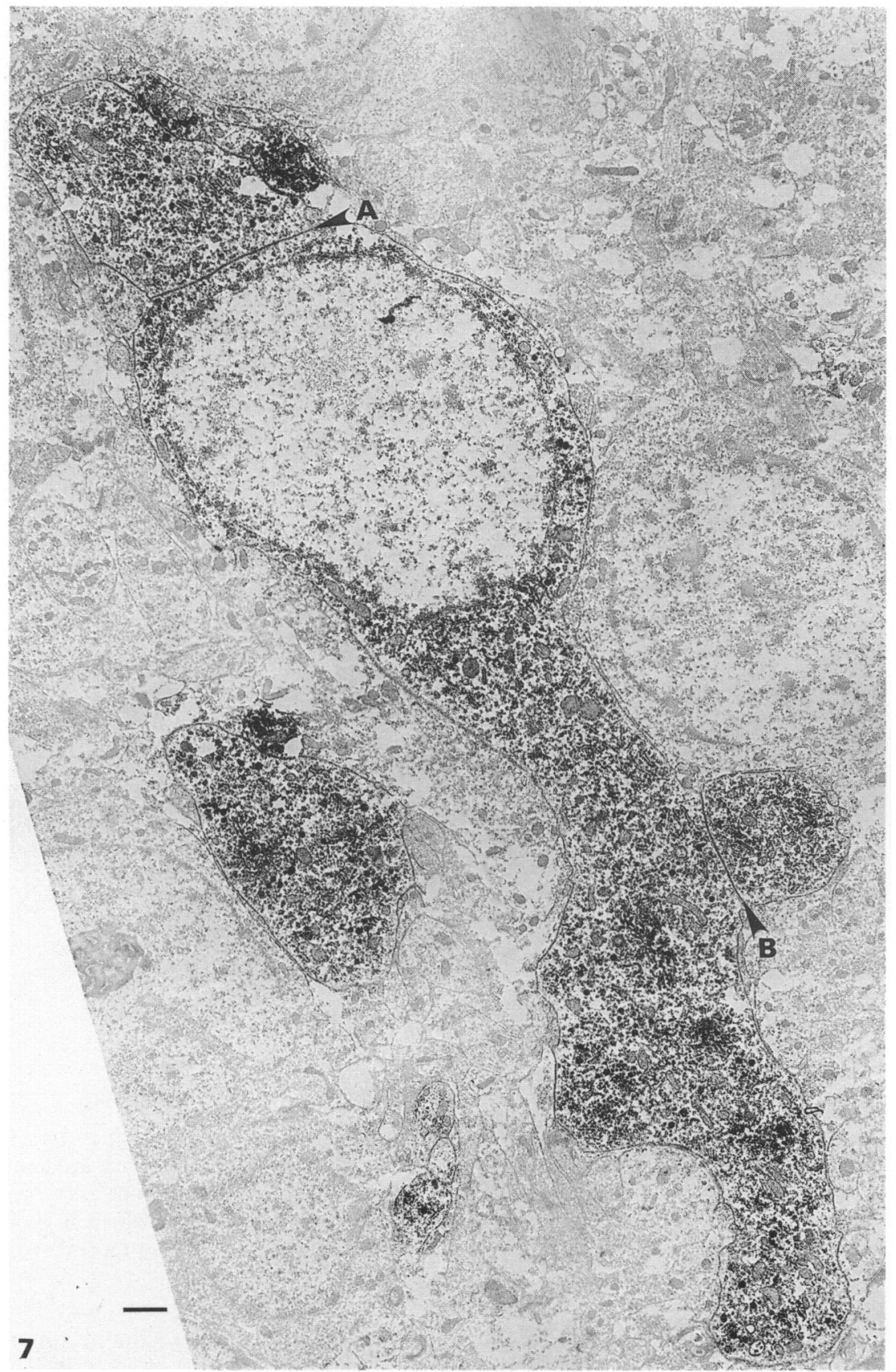

Fig. 7. An example of another Type III interaction in a female bat collected from a cave in late April. The LHRH-immunoreactive neurone exhibits direct contact with two large calibre LHRH processes. One process is juxtaposed to the perikaryon (at A), while the other contacts the process (at B). The large process at $\mathrm{A}$ is in turn contacted by several smaller fibres containing LHRH-immunoreactive granules. A detail of this latter region is shown in Fig. 8. Antiserum A-R419 (Dr Akira Arimura); bar $=1 \mu \mathrm{m}$. 


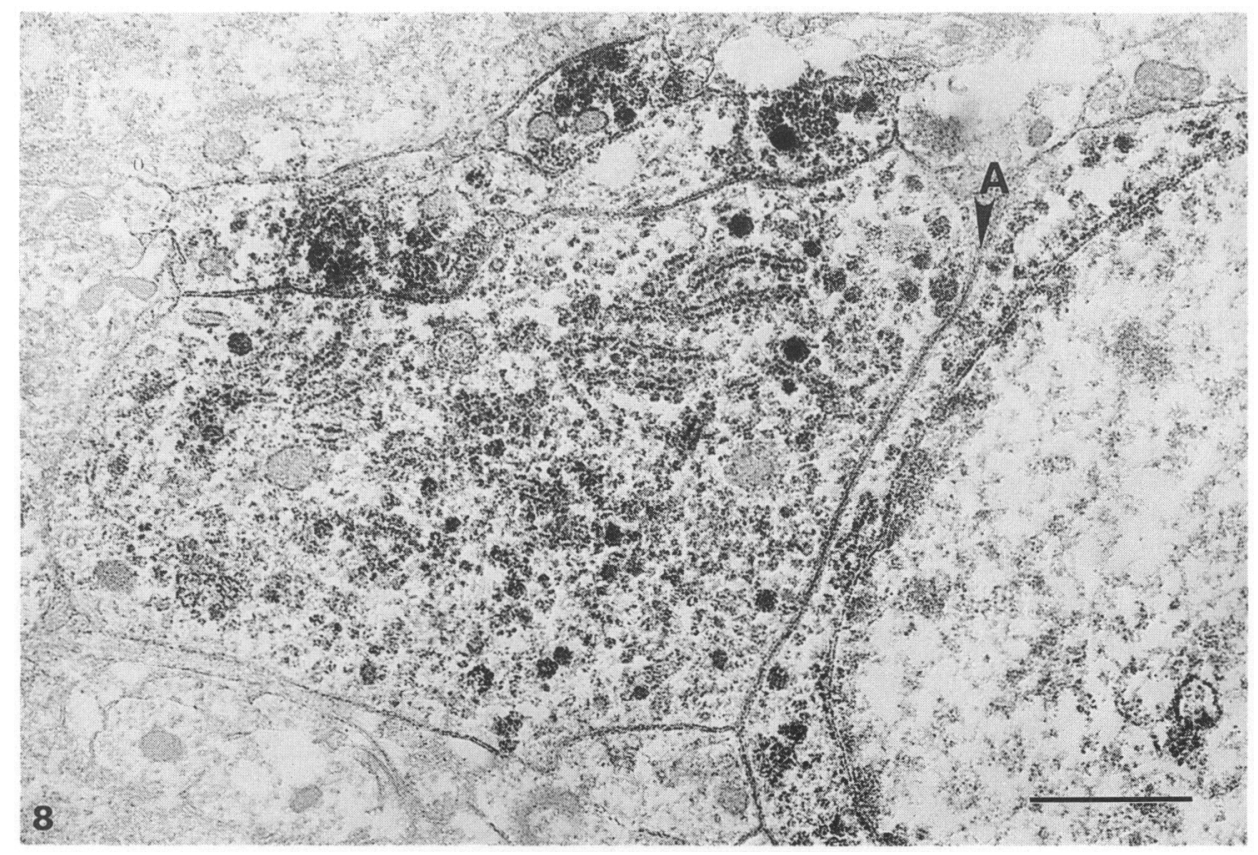

Fig. 8. The region of 'second-order' LHRH-LHRH neuronal interactions is shown at higher magnification in a section adjacent to that shown in Fig. 7. For orientation, the arrow at A indicates the site of direct membrane apposition between the large calibre process and the perikaryon. Antiserum A-R419; bar $=1 \mu \mathrm{m}$.

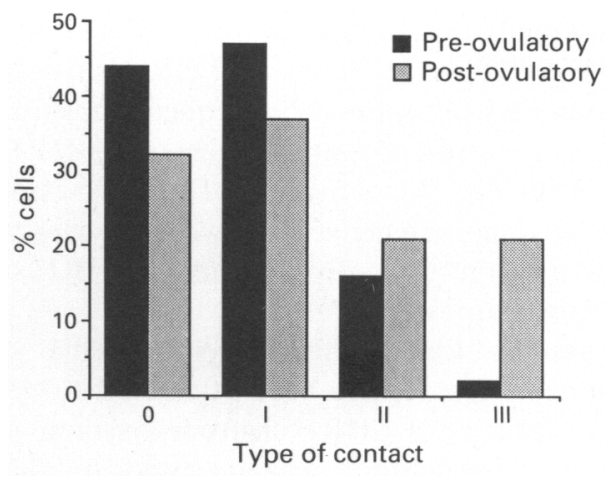

Fig. 9. A comparison of frequencies of occurrence of Type I, Type II and Type III LHRHLHRH interactions in pre- and post-ovulatory bats. For each immunopositive neurone, one photograph containing the nucleus was analysed for homologous neuronal contacts. Perikarya categorized as Type 0 had no LHRH-LHRH neuronal contacts. A neurone was counted as a single instance of Type I contact regardless of whether it exhibited more than one such contact. In cases of contact involving two perikarya with nuclei, the interaction was scored as a single instance of Type II or Type III interaction. In some instances, individual neurones exhibited independent Type I and Type II interactions, and were scored in both categories. 
perikarya were in direct apposition, and both were in contact with the same smaller immunoreactive process (Fig. 6). In other cases, immunoreactive perikarya were in direct contact with large calibre processes, which were in turn contacted by small LHRH fibres. In this study, these 'secondorder interactions' were observed much more frequently in post-ovulatory than in pre-ovulatory bats; we have also observed this phenomenon in an adult female bat collected independently from a cave environment in late April (Figs 7 \& 8).

Frequencies of occurrence of these three types of contacts in pre- and post-ovulatory bats are summarized in Fig. 9. In pre-ovulatory animals, $44 \%$ of the cells examined exhibited no LHRH contacts, and $47 \%$ showed only simple (Type I) axosomatic contacts. Type II interactions were observed in $16 \%$ of the cells, and the complex Type III arrangement was seen only once $(2 \%)$. (These percentages add up to more than $100 \%$ because a few cells exhibited independent Type I and Type II contacts.) In contrast, in post-ovulatory bats, a greater proportion of cells exhibited Type II (21\%) and especially Type III (21\%) interactions. Fewer cells exhibited Type I (37\%) or no $(32 \%)$ LHRH contacts. Neither synaptic densities nor vesicles were observed at any sites of direct membrane apposition.

LHRH neurones of pre- and post-ovulatory bats were also contacted by considerable numbers of immunonegative neuronal fibres (Fig. 4a). These sites also lacked synaptic modifications. LHRH perikarya were occasionally juxtaposed to immunonegative neuronal perikarya, exhibiting relatively long regions of direct membrane apposition (Fig. 7). Glial processes often ensheathed portions of the immunoreactive perikarya, but in no instance was a cell completely surrounded by glial elements. The extent of glial contact did not appear to vary between the two groups of bats.

\section{Discussion}

The results of this study provide strong evidence that changes in the secretory activity of LHRH neurones are associated with ovulation in the seasonally breeding little brown bat. Hypothalamic content of LHRH measured by radioimmunoassay and the number of perikarya detected by PAPimmunocytochemistry are both significantly lower after ovulation than in pre-ovulatory animals. In addition, after ovulation, pituitary stalk/neural lobe content of LHRH is significantly reduced, as is the density of immunoreactive fibres within the neural lobe.

These changes are consistent with a spring activation of LHRH secretion that is associated with arousal from hibernation and ovulation. In hibernating pre-ovulatory bats, enhanced detectability of neuronal elements and higher tissue contents of LHRH suggest that intraneuronal LHRH content is high, while secretion may be minimal. Subsequent depletion of immunoreactive LHRH from perikarya and neural lobe terminals implies increased LHRH secretion during the periovulatory period. Supporting evidence for activation of LHRH secretion in April is the depletion from the anterior pituitary of immunoreactive $\mathrm{LH}$, which occurs within the same time period (Anthony \& Gustafson, 1984). At this time of year, rates of LHRH secretion may exceed rates of synthesis, thus reducing neuronal stores.

Although it is generally assumed that the LHRH system mediates the pre-ovulatory LH surge in seasonally breeding mammals, few studies have attempted to define a dynamic relationship between ovulation and characteristics of LHRH neurones in these species. In general, however, results of previous studies involving natural seasonal cycles or photoperiodic manipulation of breeding condition are consistent with our observations. In sheep, Polkowska et al. (1980) reported that immunoreactive LHRH fibres are abundant in the median eminence of anoestrous and preovulatory ewes, whereas a substantial depletion of immunoreactive LHRH occurs on the day after ovulation. In white-footed mice (Peromyscus leucopus), Glass (1986) has compared immunocytochemical characteristics of LHRH neurones in females exposed to short-day or long-day photoperiods. Exposure to short-day conditions resulted in gonadal regression, accompanied by increased numbers of immunoreactive LHRH perikarya and increased fibre density in the median 
eminence. Increased median eminence fibre density and more intense labelling of LHRH perikarya are also induced by melatonin implants in this species (Petterborg \& Paull, 1984; Glass \& Knotts, 1987). These results all point towards high intraneuronal LHRH content in the non-breeding condition and before ovulation (suggesting inhibited secretion), followed by reduced intraneuronal content under active breeding conditions, especially after ovulation. These data also suggest that effects at the level of the LHRH system are mediated by pineal melatonin.

Non-seasonally breeding species also exhibit an association between reduced intraneuronal LHRH content and ovulation. Depletion of immunoreactive LHRH from fibres within the median eminence has been observed during the periovulatory period in rats (Polkowska \& Jutisz, 1979) as well as in guinea-pigs (Barry \& Dubois, 1974).

The binding characteristics of the primary LHRH antisera used in the present study are well defined (Arimura, 1976; Copeland et al., 1979). As both of the antisera used for immunocytochemistry (IJ-29 and A-R422) require the unmodified amidated C-terminal amino acid for binding, different immunocytochemical characteristics of neurones in pre- and post-ovulatory bats most probably reflect differences in neuronal content of mature decapeptide LHRH. Assuming that the biosynthetic precursor to LHRH in little brown bats is extended at both the Nand C-terminals, as it is in the human placental form (Seeburg \& Adelman, 1984), it is unlikely that these antisera recognized uncleaved precursor molecules in these tissues.

Within the bat forebrain, neuronal perikarya in which LHRH was depleted to undetectable levels after ovulation were not restricted to any particular nuclear group (such as those in the arcuate region), but were dispersed throughout the cell population. We therefore could not identify an anatomically distinct subpopulation that responds most dynamically during the periovulatory period. These results may indicate that in bats the widely dispersed LHRH cell population acts in concert with regard to seasonal control of gonadotrophin secretion. Alternatively, this cell population may consist of functional subpopulations that are not spatially segregated. These results contrast with those obtained for rats, in which spatially defined subpopulations of LHRH neurones respond differently to acute changes in endocrine state (King et al., 1987). Our results also suggest that neurones projecting to the infundibular stalk and neural lobe are not segregated from those giving rise to strong extrahypothalamic projections, which are characteristic of this species (King et al., 1984).

Depletion of LHRH from the stalk/neural lobe projection in the periovulatory period strongly suggests that this component of the LHRH system is directly involved in control of gonadotrophin secretion. In order to serve this function, LHRH secreted from terminals within the lower infundibular stem and neural lobe must gain access to gonadotrophs in the anterior lobe. Transport of the peptide may occur via short portal blood vessels or by direct diffusion through interstitial tissue. This latter possibility is especially relevant to the gonadotrophs that are aggregated in the portion of the anterior lobe that abuts the lower infundibular stem (Anthony \& Gustafson, 1984). Since few LHRH fibres appear to terminate in the external zone of the median eminence, transport from the lower infundibular stem and neural lobe may represent the primary route of LHRH delivery to its target cells in this mammalian species.

The cytoplasmic fine structural characterisitics of LHRH perikarya observed in this study are consistent with those previously reported for bats (Anthony \& King, 1986). The presence of rough endoplasmic reticulum, free ribosomes and mitochondria in the perinuclear cytoplasm is also consistent with descriptions of LHRH neurones in rats (Hisano et al., 1981; Kozlowski et al., 1980; Jennes et al., 1985). However, the Golgi apparatus was rarely conspicuous in labelled perikarya. In this respect, LHRH perikarya of bats differ from those of rats, in which the Golgi is evident and more strongly immunoreactive than most other organelles, and exhibits morphological changes indicative of cellular synthetic activity (King \& Seiler, 1988).

The complexity of interactions among LHRH immunopositive elements observed in this study is greater than has been reported previously for any mammalian species. The axosomatic (Type I) contacts we observed are similar to those that have been reported in rats and monkeys (Leranth et 
al., 1985; Witkin \& Silverman, 1985; Pelletier, 1987; Thind \& Goldsmith, 1988), although we did not observe synaptic densities at these sites, perhaps as a result of using detergent during immunolabelling. In contrast, extensive areas of direct somatic apposition or similar contacts involving large-caliber processes have not been previously described in these species, although one instance of direct somatic apposition was reported in a golden hamster (Lehman \& Silverman, 1988). Most extraordinary in these bats, however, are the complex networks of LHRH-LHRH neuronal contact that involve aggregates of perikarya and processes, and those that exhibit 'second-order' interactions.

The more common occurrence of these complexes in post-ovulatory bats collected in April suggests that these interactions are involved in the spring activation of the LHRH system. At the onset of the active season, such extensive contacts between elements of the LHRH system may promote synchronous pulsatile activity of these neurones. Evidence of similar morphological plasticity has been reported for oxytocin neurones within the supraoptic nucleus of rats. In this cell population, direct membrane apposition between perikarya, and between dendrites and perikarya, increases dramatically during late pregnancy and lactation (Hatton \& Tweedle, 1982; Theodosis \& Poulain, 1984; Theodosis et al., 1986a). These sites of apposition often lack evidence of synaptic specializations (as do those in our study). However, the fact that increased physical association between neurones coincides with augmented secretion of oxytocin and synchronous activation of the cell population (Belin et al., 1984) suggests that these contacts contribute in some way to electrical coupling, perhaps via gap junctions or ephaptic transmission of neural impulses (Ramón \& Moore, 1978; Alonso et al., 1985).

Association of complex LHRH-LHRH neuronal contacts with activation of this neuronal system implies that LHRH may influence its own secretion. Intracerebroventricular infusion of oxytocin induces a restructuring of the supraoptic nucleus equivalent to that associated with lactation (Theodosis et al., 1986b), suggesting that enhanced central secretion of oxytocin during lactation (paralleling secretion into peripheral circulation) may promote formation of neuronal contacts. Thus, these contacts appear to play a role in potentiation of oxytocin secretion by oxytocin itself.

Negative feedback effects may also be mediated by direct contacts between homologous peptidergic elements. In rats, pituitary response to intracerebroventricular injection of LHRH suggests that such an ultrashort feedback loop may contribute to regulation of LHRH in vivo (Bedran de Castro et al., 1985; DePaolo et al., 1987). Results of in-vitro perifusion experiments also support this hypothesis (Zanisi et al., 1987).

Autoregulation in peptidergic systems (whether stimulatory or inhibitory) could in theory be mediated by contacts between different neurones and/or by contacts between different parts of the same neurone (e.g. recurrent axon collaterals). Electron microscopic immunocytochemistry has been widely used to confirm synaptic (and non-synaptic) relationships between homologous neural elements in several hypothalamic systems (Chen \& Pelletier, 1983; Kiss \& Williams, 1983; Tsuruo et al., 1984; Alonso et al., 1985; Liposits et al., 1985; Horváth \& Palkovits, 1988). However, thin sectioning usually obscures the source of presynaptic fibres and it is technically difficult to establish sites of potential communication as intraneuronal or interneuronal. In this study, however, we observed adjacent profiles of LHRH perikarya, both of which contained nuclei, confirming these as interneuronal contacts. Furthermore, in the complex networks of LHRH-LHRH neuronal contacts we have described, it is unlikely that all of the processes involved are parts of the same neurone. Thus, while the occurrence of recurrent collateralization cannot be ruled out in this species, there is both direct and indirect evidence for the existence of interneuronal LHRH contacts.

Since all of the perikarya included in this fine structural study were located within the medial basal hypothalamus, we cannot generalize our findings to the entire cell population. LHRH neurones in parts of the forebrain where they are more sparsely distributed may not develop networks of contact as elaborate as those aggregated in the region of the arcuate nuclei. Further- 
more, the role that glial cells and their processes may play in seasonal changes in these networks has not been elucidated in this study. However, even in hibernating bats, we do not encounter LHRH neurones completely surrounded by glial processes, as did Lehman et al. (1988) in anoestrous ewes. This may reflect the fact that these bats do not experience a true anoestrous period, such as is characteristic of most seasonal breeders. Instead, females overwinter in an arrested pre-ovulatory condition which is unique to temperate-zone hibernating bats.

We thank Dr Akira Arimura (US-Japan Biomedical Research Laboratories, Tulane University, Belle Chase, LA, USA), Dr Ivor Jackson (Division of Endocrinology, Rhode Island Hospital, Providence, RI, USA) and Dr Terry Nett (Department of Physiology, Colorado State University, Fort Collins, CO, USA) for gifts of LHRH antisera; Dr Paul McMillan and Sara Spangenberger of the Rhode Island Hospital Core Research Facility for valuable help with electron microscopy; and Revella Harmon and Carla Melucci for technical assistance. These studies were supported by NSF grant DCB-8510370 (to E.L.P.A.), NIH grant RO1 HD19803-02 (to J.C.K.), and a Rhode Island College Faculty Research Grant (to E.L.P.A.).

\section{References}

Alonso, G., Tapia-Arancibia, L. \& Assenmacher, I. (1985) Electron microscopic immunocytochemical study of somatostatin neurons in the periventricular nucleus of the rat hypothalamus with special reference to their relationships with homologous neuronal processes. Neuroscience 16, 297-306.

Anthony, E.l.P. \& Gustafson, A.W. (1984) Seasonal variations in pituitary LH-gonadotropes of the hibernating bat Myotis lucifugus lucifugus: an immunohistochemical study. Am. J. Anat. 170, 101-115.

Anthony, E.L.P. \& King, J.C. (1986) Combined light and electron microscope immunocytochemical localization of scattered peptidergic neurons in the central nervous system. Am. J. Anat. 175, 179-195.

Anthony, E.L.P., King, J.C. \& Stopa, E.G. (1984) Immunocytochemical localization of LHRH in the median eminence, infundibular stalk, and neurohypophysis: evidence for multiple sites of releasing hormone secretion in humans and other mammals. Cell Tissue Res. 236, 5-14.

Anthony, E.L.P., Wu, P., Bruhn, T.O. \& Jackson, I.M.D. (1987) Characterization of LH-RH immunoreactivity in mammalian pituitary neural lobe by HPLC. Brain Res. 424, 258-263.

Arimura, A. (1976) Recent developments in the study of hypothalamic hormones with special reference to LH-RH and somatostatin. Folia endocrinol. jap. 52, 1159-1183.

Barry, J. \& Dubois, M.P. (1974) Immunofluorescence study of the preoptico-infundibular LH-RH neurosecretory pathway of the guinea pig during the estrous cycle. Neuroendocrinology 15, 200-208.

Bedran de Castro, J.C., Khorram, O. \& McCann, S.M. (1985) Possible negative ultra-short loop feedback of luteinizing hormone releasing hormone (LHRH) in the ovariectomized rat. Proc. Soc. exp. Biol. Med. 179, 132-135.

Belin, V., Moos, F. \& Richard, P. (1984) Synchronization of oxytocin cells in the hypothalamic paraventricular and supraoptic nuclei in suckled rats: direct proof with paired extracellular recordings. Expl Brain Res. 57, 201-203.
Chen, Y.Y. \& Pelletier, G. (1983) Demonstration of contacts between proopiomelanocortin neurons in the rat hypothalamus. Neurosci. Lett. 43, 271276.

Copeland, K.C., Aubert, M.L., Rivier, J. \& Sizonenko, P.C. (1979) Luteinizing hormone-releasing hormone: sequential versus conformational specificity of antiluteinizing hormone-releasing hormone sera. Endocrinology 104, 1504-1512.

DePaolo, L.V., King, R.A. \& Carrillo, A.J. (1987) In vivo and in vitro examination of an autoregulatory mechanism for luteinizing hormone-releasing hormone. Endocrinology 120, 272-279.

Glass, J.D. (1986) Short photoperiod-induced gonadal regression: Effects on the gonadotropin-releasing hormone (GnRH) neuronal system of the whitefooted mouse, Peromyscus leucopus. Biol. Reprod. 35, 733-743.

Glass, J.D. \& Knotts, L.K. (1987) A brain site for the antigonadal action of melatonin in the white-footed mouse (Peromyscus leucopus): involvement of the immunoreactive GnRH neuronal system. Neuroendocrinology 46, 48-55.

Gustafson, A.W. \& Belt, W.D. (1981) The adrenal cortex during activity and hibernation in the male little brown bat, Myotis lucifugus lucifugus: annual rhythm of plasma cortisol levels. Gen. comp. Endocrinol. 44, 269-278.

Hatton, G.I. \& Tweedle, C.D. (1982) Magnocellular neuropeptidergic neurons in hypothalamus: Increases in membrane apposition and number of specialized synapses from pregnancy to lactation. Brain Res. Bull. 8, 197-204.

Hisano, S., Kawano, H., Maki, Y. \& Daikoku, S. (1981) Electron microscopic study of immunoreactive LHRH perikarya with special reference to neuronal regulation. Cell Tissue Res. 220, 511-518.

Horváth, S. \& Palkovits, M. (1988) Synaptic interconnections among growth hormone-releasing hormone (GHRH)-containing neurons in the arcuate nucleus of the rat hypothalamus. Neuroendocrinology 48, 471-476. 
Jennes, J., Stumpf, W.E. \& Sheedy, M.E. (1985) Ultrastructural characterization of gonadotropin-releasing hormone (GnRH)-producing neurons. J. comp. Neurol. 232, 534-547.

King, J.C. \& Seiler, G.R. (1988) Ultrastructural evidence suggests variations in biosynthesis and processing within LH-RH neurons as a function of ovariectomy in rats. Brain Res. 452, 127-140.

King, J.C., Anthony, E.L.P., Gustafson, A.W. \& Damassa, D.A. (1984) Luteinizing hormone-releasing hormone (LH-RH) cells and their projections in the forebrain of the bat Myotis lucifugus lucifugus. Brain Res. 298, 289-301.

King, J.C., Kugel, G., Zahniser, D., Wooledge, K., Damassa, D.A. \& Alexsavich, B. (1987) Changes in populations of LHRH-immunopositive cell bodies following gonadectomy. Peptides 8, 721-735.

Kiss, J.Z. \& Williams, T.H. (1983) ACTH-immunoreactive boutons form synaptic contacts in the hypothalamic arcuate nucleus of rat: evidence for local opiocortin connections. Brain Res. 263, 142-146.

Kozlowski, G.P., Chu, L., Hostetter, G. \& Kerdelhué, B. (1980) Cellular characteristics of immunolabeled luteinizing hormone releasing hormone (LHRH) neurons. Peptides 1, 37-46.

Lehman, M.N. \& Silverman, A.-J. (1988) Ultrastructure of luteinizing hormone-releasing hormone (LHRH) neurons and their projections in the golden hamster. Brain Res. Bull. 20, 211-221.

Lehman, M.N., Karsch, F.J., Robinson, J.E. \& Silverman, A.-J. (1988) Ultrastructure and synaptic organization of luteinizing hormone-releasing hormone (LHRH) neurons in the anestrous ewe. J. comp. Neurol. 273, 447-458.

Leranth, Cs., Segura, L.M.G., Palkovits, M., MacLusky, N.J., Shanabrough, M. \& Naftolin, F. (1985) The LHRH-containing neuronal network in the preoptic area of the rat: demonstration of LH-RH-containing nerve terminals in synaptic contact with LH-RH neurons. Brain Res. 345, 332-336.

Liposits, Zs., Paull, W.K., Sétáló, G. \& Vigh, S. (1985) Evidence for local corticotropin releasing factor (CRF)-immunoreactive neuronal circuits in the paraventricular nucleus of the rat hypothalamus. Histochemistry 83, 5-16.

Pelletier, G. (1987) Demonstration of contacts between neurons staining for LHRH in the preoptic area of the rat brain. Neuroendocrinology 46, 457-459.

Petterborg, L.J. \& Paull, W.K. (1984) An immunocytochemical study of the luteinizing hormone-releasing hormone (LHRH) system in the white-footed mouse: effect of blinding and melatonin. J. Pineal Res. 1, 371-380.

Polkowska, J. \& Jutisz, M. (1979) Local changes in immunoreactive gonadotropin releasing hormone in the rat median eminence during the estrous cycle. Correlation with the pituitary luteinizing hormone. Neuroendocrinology 28, 281-288.

Polkowska, J., Dubois, M.-P. \& Domański, E. (1980) Immunocytochemistry of luteinizing hormone releasing hormone (LHRH) in the sheep hypothalamus during various reproductive stages. Cell Tissue Res. 208, 327-341.

Ramón F. \& Moore, J.W. (1978) Ephaptic transmission in squid giant axons. Am. J. Physiol. 234, C162-C169.

Seeburg, P.H. \& Adelman, J.P. (1984) Characterization of cDNA for precursor of human luteinizing hormone releasing hormone. Nature, Lond. 311, 666-668.

Theodosis, D.T. \& Poulain, D.A. (1984) Evidence for structural plasticity in the supraoptic nucleus of the rat hypothalamus in relation to gestation and lactation. Neuroscience 11, 183-193.

Theodosis, D.T., Chapman, D.B., Montagnese, C., Poulain, D.A. \& Morris, J.F. (1986a) Structural plasticity in the hypothalamic supraoptic nucleus at lactation affects oxytocin-, but not vasopressinsecreting neurones. Neuroscience 17, 661-678.

Theodosis, D.T., Montagnese, C., Rodriguez, F., Vincent, J.D. \& Poulain, D.A. (1986b) Oxytocin induces morphological plasticity in the adult hypothalamoneurohypophysial system. Nature, Lond. 322, 738 740.

Thind, K.K. \& Goldsmith, P.C. (1988) Infundibular gonadotropin-releasing hormone neurons are inhibited by direct opioid and autoregulatory synapses in juvenile monkeys. Neuroendocrinology 47, 203-216.

Tsuruo, Y., Hisano, S. \& Daikoku, S. (1984) Morphological evidence for synaptic junctions between substance P-containing neurons in the arcuate nucleus of the rat. Neurosci. Lett. 46, 6569.

Wimsatt, W.A. (1944) Growth of the ovarian follicle and ovulation in Myotis lucifugus lucifugus. Am. J. Anat. 74, 129-173.

Witkin, J.W. \& Silverman, A.-J. (1985) Synaptology of luteinizing hormone-releasing hormone neurons in rat preoptic area. Peptides 6, 263-271.

Zanisi, M., Messi, E., Motta, M. \& Martini, L. (1987) Ultrashort feedback control of luteinizing hormonereleasing hormone secretion in vitro. Endocrinology 121, 2199-2204.

Received 8 March 1989 